\title{
Amphiphilic Poly(3-hydroxy alkanoate)s: Potential Candidates for Medical Applications
}

\author{
Baki Hazer \\ Department of Chemistry, Zonguldak Karaelmas University, 67100 Zonguldak, Turkey \\ Correspondence should be addressed to Baki Hazer, bhazer2@yahoo.com \\ Received 3 December 2009; Accepted 31 December 2009 \\ Academic Editor: Shanfeng Wang \\ Copyright () 2010 Baki Hazer. This is an open access article distributed under the Creative Commons Attribution License, which \\ permits unrestricted use, distribution, and reproduction in any medium, provided the original work is properly cited. \\ Poly(3-hydroxy alkanoate)s, PHAs, have been very attractive as biomaterials due to their biodegradability and biocompatibility. \\ These hydrophobic natural polyesters, PHAs, need to have hydrophilic character particularly for drug delivery systems. In this \\ manner, poly(ethylene glycol) (PEG) and hydrophilic functional groups such as amine, hydroxyl, carboxyl, and sulfonic acid have \\ been introduced into the PHAs in order to obtain amphiphilic polymers. This review involves in the synthesis and characterization \\ of the amphiphilic PHAs.
}

\section{Introduction}

Biomaterials have been widely used in medical applications, such as drug delivery, tissue engineering, devicebased therapies, and medical imaging [1, 2]. Synthetic and naturally occurring polymers have played important role in the treatment of disease and the improvement of health care. Among them, PHAs are promising materials for biomedical applications in tissue engineering and drug delivery system because they are natural, renewable, biodegradable, and biocompatible thermoplastics. PHAs have been used to develop devices, including sutures, nerve repair devices, repair patches, slings, cardiovascular patches, orthopedic pins, adhesion barriers, stents, guided tissue repair/regeneration devices, articular cartilage repair devices, nerve guides, tendon repair devices, bone-marrow scaffolds, tissue engineered cardiovascular devices, and wound dressing. However the direct use of these polyesters has been hampered by their hydrophobic character and some physical shortcomings [3]. The key to biocompatibility of biomedical implantable materials is to render their surface in a way that minimizes hydrophobic interaction with the surrounding tissue. Therefore, hydrophilic groups have been introduced into the PHAs in order to obtain amphiphilic polymer. This review has been focused on the chemically modified PHAs with enhanced hydrophilic character as biomaterials for medical applications.

\section{PHAs}

PHAs are accumulated as intracellular granules as a result of a metabolic stress upon imbalanced growth due to a limited supply of an essential nutrient and the presence of an excess of a carbon source. These novel biopolymers have material properties ranging from rigid and highly crystalline to flexible, rather amorphous and elastomeric. There have been many studies reported on the modification reactions to enhance mechanical and thermal properties to prepare new biomaterials for the medical applications [4-13]. PHAs can be classified into three groups based on the number of carbon atoms in the monomer units: short-chain-length (sclPHA) containing 3-5 carbon atoms that are produced by Ralstonia eutropha (also referred Watersia eutropha, A. Eutrophus), medium-chain-length ( $m c l$ PHA) containing 6-14 carbon atoms, and long-chainlength (lclPHAs), with more than 14 carbon atoms [14, 15]. Pseudomonas oleovorans is a very versatile microrgnism for PHA production because it can produce medium chain length polyesters ( $m c l$ PHA) and long chain length polyesters (lclPHA) from a wide variety of carbon substrates. These 
TABLE 1: Classification of the bacterial polyesters.

\begin{tabular}{|c|c|c|c|c|c|c|}
\hline \multirow{3}{*}{ Carbon source } & \multicolumn{3}{|c|}{$\left[-\mathrm{O}-\mathrm{C}_{\left.\mathrm{R}_{(\mathrm{PHA})}^{\mathrm{CH}}-\mathrm{CH}_{2}-\mathrm{C}-\right]}^{\mathrm{O}}\right.$} & & & \\
\hline & \multicolumn{3}{|c|}{ Poly(3-hydroxy alkanoate) (PHA) } & \multicolumn{3}{|c|}{ Thermal and mechanical properties } \\
\hline & Type & Side chain $(\mathrm{R})$ & Name* & $T_{g}\left({ }^{\circ} \mathrm{C}\right)$ & $T_{m}\left({ }^{\circ} \mathrm{C}\right)$ & Elongation (\%) \\
\hline Sugar, glucose, acetic acid & Short chain length & $\begin{array}{l}\text { Methyl, } \\
\text { ethyl }\end{array}$ & $\begin{array}{l}\text { PHB } \\
\text { PHV }\end{array}$ & 15 & 170 & 5 \\
\hline Alkanoic acids, alkanes, and alkanols & Medium chain length & $\begin{array}{l}\text { propyl, } \\
\text { butyl, } \\
\text { pentyl, } \\
\text { hexyl, } \\
\text { heptyl } \\
\end{array}$ & $\begin{array}{l}\text { PHHx } \\
\text { PHHp } \\
\text { PHO } \\
\text { PHN } \\
\text { PHD } \\
\end{array}$ & -40 & 60 & 800 \\
\hline Plant oily acids & Long chain length & $\begin{array}{r}\text { More than } 14 \\
\text { per repeatin }\end{array}$ & $\begin{array}{l}\text { arbon } \\
\text { unit }\end{array}$ & -50 & 40 & Soft, sticky \\
\hline
\end{tabular}

types of the bacterial polyesters have been summarized in Table 1 .

\section{Amphiphilic PHAs}

Amphiphilic polymers can be synthesized by introducing hydrophilic groups such as hydroxyl, carboxyl, amine, glycol, and hydrophilic polymers such as PEG, poly(vinyl alcohol), polyacryl amide, poly acrylic acids, hydroxy ethyl methacrylate, poly vinyl pyridine, and poly vinyl pyrrolidone to a hydrophobic moiety. Because of their ability to form micelles, amphiphilic block copolymers are strong candidates for potential applications as emulsifiers, dispersants, foamers, thickeners, rinse aids, and compatibilizers [16, 17]. Similarly, amphiphilic PHAs can also be synthesized by introducing hydrophilic groups such as hydroxyl, carboxyl, amine, sulfonic acid, ethylene glycol, and PEG. PEG is a polyether that is known for its exceptional blood and tissue compatibility. It is used extensively as biomaterial in a variety of drug delivery vehicles and is also under investigation as surface coating for biomedical implants. PEG, when dissolved in water, has a low interfacial free energy and exhibits rapid chain motion, and its large excluded volume leads to steric repulsion of approaching molecules [18]. These properties make PEG excellent biocompatible material. Hydroxylation of the PHAs can be carried out by using both biosynthetic and chemical modification. The biosynthetic hydroxylation of the PHAs has successfully been reviewed by Foster, recently [19]. Chemical modifications of the PHAs have been extensively studied $[6,9,15,20-24]$. In this review, selective chemical modification reactions in order to obtain amphiphilic PHAs will be discussed.

\section{Synthesis of Amphiphilic PHAs}

Selective chemical modification of the PHAs involves functionalization and grafting reactions of the PHAs. Hydrophilic groups such as hydroxyl, carboxyl, amine, glycol and sulfonic acid can be introduced into the PHAs by means of functionalization. In grafting reactions, some hydrophilic groups have been attached in the PHA chain to obtain amphiphilic polymer.

4.1. Transesterification. Some ester group(s) of the PHA is exchanged with an alcohol in transesterification process. Transesterification is carried out in melt or in solution. Hydroxylation of the PHBs via chemical modification is usually achieved by the transesterification reactions to obtain diol ended PHB. Transesterification reactions in the melt between poly(ethylene glycol), mPEG, and PHB yield diblock amphiphilic copolymer with a dramatic decrease in molecular weight [25]. Catalyzed transesterification in the melt is used to produce diblock copolymers of poly ([R]-3-hydroxybutyric acid), PHB, and monomethoxy poly(ethylene glycol), mPEG, in the presence of a catalyst, in a one-step process. The formation of diblocks is accomplished by the nucleophilic attack from the hydroxyl endgroup of the mPEG catalyzed by bis(2-ethylhexanoate) tin.

When the transesterification reaction between $\mathrm{PHB}$ and ethylene glycol in diglyme as a solvent is carried out, the telechelic PHB with MW at around 2000 Dalton is obtained [26]. Stannous octanoate as a transesterification catalyst causes the reaction of carboxylic end group and diol, quantitatively. Basically, short chain diol or polyol moiety can rarely renders a hydrophilic character to the longer hydrophobic PHA. Therefore amphiphilic character of the telechelic PHAs and PEGylated PHAs have been stood poor.

Telecehelic PHB obtained by this way can be used in the preparation of the polyester urethanes via diisocyanate chain extension reaction with synthetic aliphatic polyester as soft segment $[27,28]$. PHB-g-Poly ( $\varepsilon$-caprolactone) (PCL) graft copolyester urethane samples exhibited the elongation at break up to $900 \%$. 


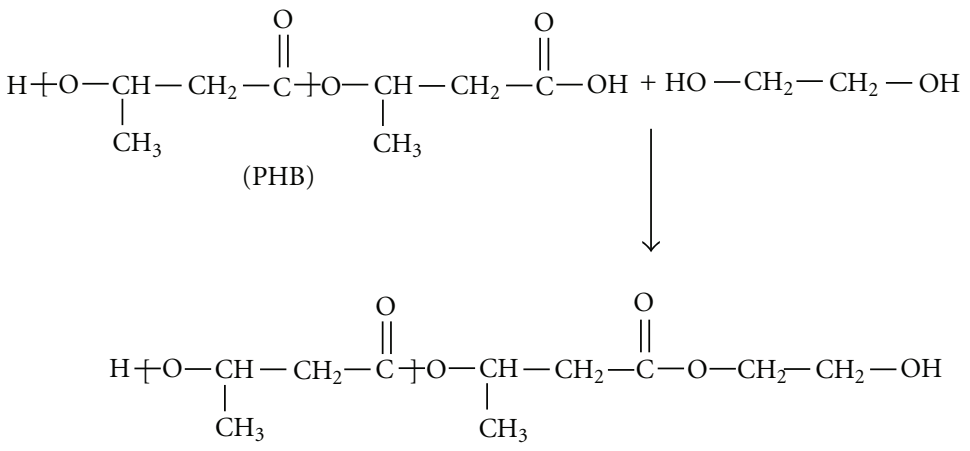

(PHB-diol)

(a)

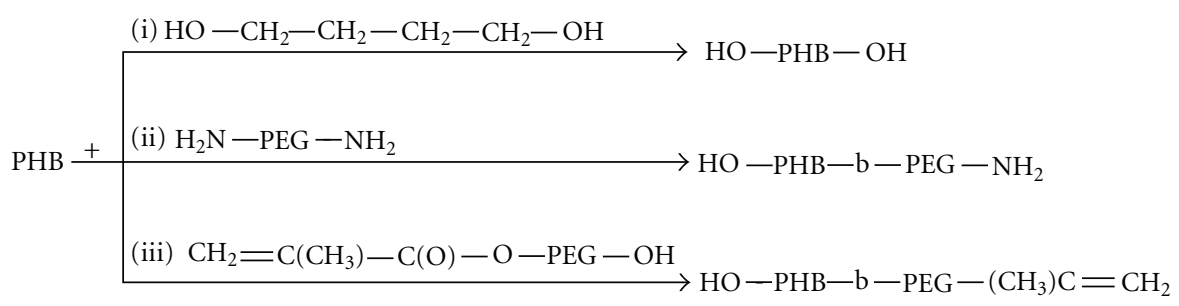

(b)

FIgURE 1: (a) Formation of the diol ended PHB via transesterification in the presence of ethylene glycol. (b) Transesterification reactions of PHB with (i) butane diol, (ii) transamidation with bisaminopropyl ended PEG, and (iii) transesterification reactions of PHB with methacryloyl oxy ethylene glycol in solution.

Two segmented biodegradable poly(ester-urethane) series, based on bacterial PHB as the hard segments, and either PCL or PBA as the soft segments, were easily synthesized by one-step solution polymerizations. Transesterification reaction of PHB with methacryloyl oxy poly(ethylene glycol) (MW: 526), poly(ethylene glycol) bis (2-aminopropyl ether) with MW 1000 and 2000 was achieved to obtain PHB-b-PEG telechelic diblock copolymers [29]. Similarly, telechelic PHB can also be obtained by transesterification with 1,4-butane diol in 1,2-dichloro benzene under reflux conditions. The transesterification reactions can be designed in Figure 1.

4.2. Carboxylation and Hydroxylation of the Pendant Double Bonds. Most used unsaturated PHAs are mclPHAs obtained from unsaturated edible oils and synthetic olefinic substrates. When Pseudomonas oleovorans is grown on unsaturated carbon source such as soybean oily acids, 7-octenoic acid and 10-undecenoic acid, unsaturated PHAs are obtained [30-33]. Figure 2 shows the synthesis of the unsaturated PHAs.

Microbial polyesters containing unsaturated side chains are open the way for chemical modification reactions to prepare PHA derivatives. Pendent double bonds of the poly(3-hydroxy octanoate-co-10-undecenoate), PHOU, can be oxidized to the diol (PHOU-diol) and carboxylic acid (PHOU-COOH). $\mathrm{KMnO}_{4}$ is used as an oxidizing agent. In mild conditions PHOU-diol is obtained [34]. While PHOU was insoluble in a polar solvent, PHOU-diol was soluble in methanol, acetone/water $(80 / 20, \mathrm{v} / \mathrm{v})$, and DMSO, even with $40 \%-60 \%$ of double bonds unconverted, but it was insoluble in nonpolar solvents such as chloroform, THF, acetone. Figure 3 shows the PHOU-diol. The use of $\mathrm{NaHCO}_{3}$ even in hot solution $\left(55^{\circ} \mathrm{C}\right)$ resulted mainly in diol groups, not carboxylic groups, while the same reaction at room temperature using $\mathrm{KHCO}_{3}$, led to the conversion of the pendant unsaturated groups to the carboxyl groups [35]. Figure 4 shows the $\mathrm{PHOU}$ with pendant carboxyl groups.

Carboxylation of $\mathrm{PHOU}$ using $\mathrm{OsO}_{4}$ as oxidant can be performed with the small decrease in MW after the reaction [36]. The quantitative hydroxylation of pendant vinyl groups of poly(3-hydroxy-10-undecenoate) (PHU) with the use of either the borobicyclononane or the borane-tetrahydrofuran complex is also achieved in high yield [37, 38]. After hydroxylation, the thermal stability and the molecular weight of the hydroxylated PHU showed small decreases; however, full solubility in methanol and almost full solubility in water are achieved [37, 38].

Water wettability of saturated PHAs, poly(3-hydroxy butyrate) (PHB) and poly(3-hydroxy butyrate-co-3-hydroxy hexanoate) (PHBHHx) can also be improved by carboxyl ion implantation. Ion implantation is performed at energy of $150 \mathrm{keV}$ with fluences ranging from $5 \times 10^{12}$ to $1 \times$ $10^{15}$ ions $/ \mathrm{cm}^{2}$. Contact angle measurements are confirmed that the ion implantation improves the water wettability [39].

Epoxidation of the unsaturated polyester with $\mathrm{m}$ chloroperbenzoic acid, as a chemical reagent, yields to 
Unsaturated microbial polyesters (PHA)s

Poly(3-hydroxy-octanoate-co-10-undecenoate) (PHOU)

Poly(3-hydroxy alkenoate) from soybean oil (PHA-Sy)<smiles>C=CCCCCCCCCC(=O)O</smiles>

10-undecenoic $(\mathrm{U})$ acid<smiles>CCCCCCCC(=O)O</smiles>

Octanoic $(\mathrm{O})$ acid

Pseudomonas oleovorans

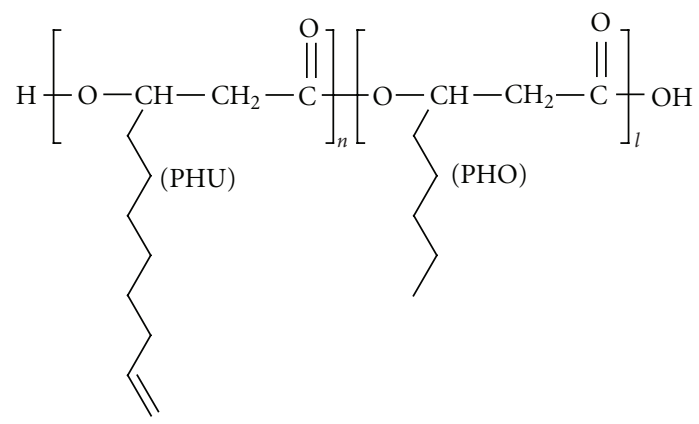

PHOU<smiles></smiles>

Soybean oil (Sy)

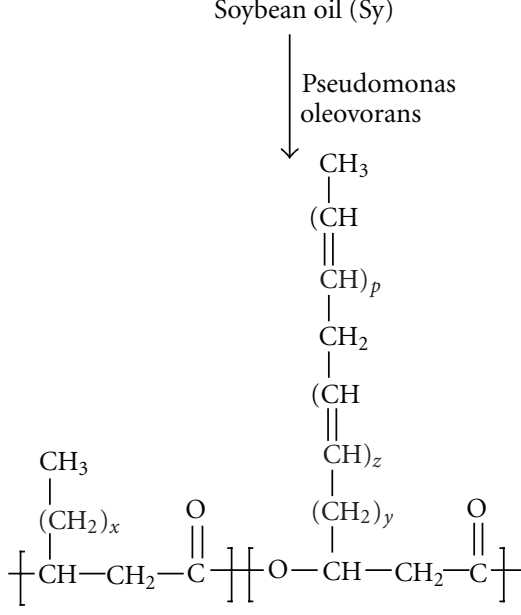

PHA-Sy

Figure 2: Synthesis of two types of unsaturated PHAs from Pseudomonas oleovorans (i) grown on soybean (PHA-Sy) and (ii) 10-undecenoic acid and octanoic acid (PHOU).<smiles>C=CCC(CC(=O)OC(CC(=O)CC(CC)CO)CC(C)(C)C)OC(C)(C)C</smiles>

FIGURe 3: PHOU with pendant hydroxyl groups (PHOU-OH).<smiles>C=CCC(CC(=O)OC(CC(=O)O)CC(=O)CC(C)C)OC(C)(C)C</smiles>

FIgURE 4: PHOU with pendant carboxylic acids (PHOU-COOH).

quantitative conversions of the unsaturated groups into epoxy groups [40]. Primary and secondary amines can be reacted with epoxide groups to yield hydrophilic compounds. Reaction between hexamethylene diamine with epoxidized PHOU provides cross-linked polyester [41].

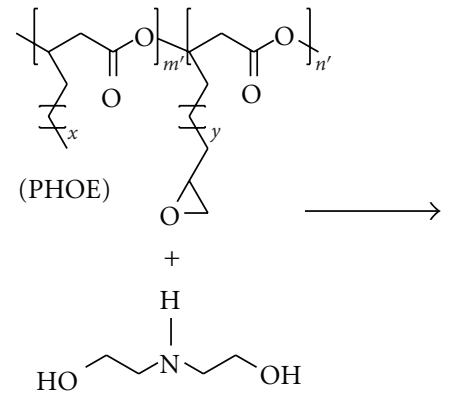

(Diethanol amine)

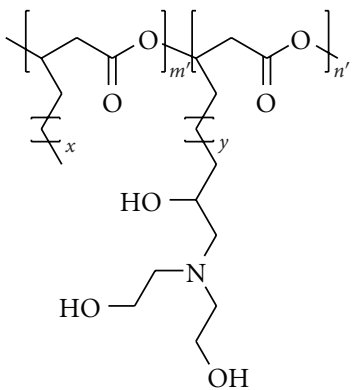

(PHON)
FIGURE 5: The conversion reaction of epoxidized-PHOU (PHOE) to hydroxylated PHOU in the presence of diethanol amine (PHON).

Enhenced hydrophilicity of the PHOU has recently been achieved by the reaction between epoxidized PHOU and diethanol amine to give highly hydrophilic polyester, PHON [42]. The first reaction involved the transformation of the vinyl-terminated side chains of PHOU to epoxide groups (PHOE). Figure 5 shows the conversion reaction of epoxidized PHOU (PHOE) to hydroxylated PHOU in the presence of diethanol amine. 
The successful side chain conversion was further substantiated by the change in solubility when converting PHOU to PHOE to PHON. As the functionalized side chains became more polar, the polymer became soluble in more polar solvents. In this aspect, PHON was soluble in water.

4.3. Quarternization and Sulfonation of the PHAs. Halogenation of the polymers is a versatile method to open the way for further functionalization $[29,43,44]$. Addition of the chlorine and bromine into the double bond is quantitative and halogenated PHAs can be easily obtained by this way [29]. Chlorination is performed by either the addition to double bonds of the unsaturated PHA obtained from soybean oil (PHA-Sy) or substitution reactions with saturated hydrocarbon groups $[43,44]$. Chlorination of the sticky, soft PHA-Sy with double bond provides polyester with hard, brittle, and crystalline physical properties depending on the chlorine content. By this way, it is possible to introduce $35 \mathrm{wt} \%$ chlorine to the PHA. In case of the chlorinated PHO, glass transition temperature has been shifted to $+2^{\circ} \mathrm{C}$ from $-40^{\circ} \mathrm{C}$ [44]. For further functionalization, quaternization reactions of the chlorinated PHA with triethylamine (or triethanol amine) can be performed. Additionally, aqueous solution of $\mathrm{Na}_{2} \mathrm{~S}_{2} \mathrm{O}_{3} \cdot 5 \mathrm{H}_{2} \mathrm{O}$ can be reacted with solution of chlorinated PHA (PHA-Cl) in acetone to give sulfonate derivative of the $\mathrm{PHO}$ [44].

\subsection{Grafting Reactions of the PHAs}

4.4.1. Chitosan Grafting. Chemical modifications of chitosan by grafting method are important to prepare multifunctional materials in different fields of application and to improve its chemical, physical, and mechanical properties $[45,46]$. Chitosan-g-Poly(3-hydroxy butyrate-co-3-hydroxy valerate) (PHBV) graft copolymer was synthesized and grafting of linoleic acid on chitosan were performed by condensation reaction under vacuum at $90-95^{\circ} \mathrm{C}$. Chitosan-g-PHBV graft copolymers exhibit different solubility behavior such as solubility, insolubility, or swelling in $2 \mathrm{wt} \%$ acetic acid and in water as a function of degree of substitution of $\mathrm{NH}_{2}$ while pure chitosan does not swell in water. Chitosan-g-PHBV graft copolymer is shown in Figure 6.

4.4.2. Sugar Grafting. Glycopolymers are emerging as a novel class of neoglycoconjugates useful for biological studies and they are prepared either by copolymerization or grafting methods [47]. Since it has been shown that thiosugars are potent tools in glycobiology, 1-thiomaltose derivatives has been grafted onto PHAs in two ways [48]; the thiol sugar is added to the double bond and the reaction between thiol sugar and bromo end groups of polyester biosynthesized from 11-bromoundecanoic acid [49]. These new grafted polymers are insoluble in dichloromethane and chloroform, but very soluble in $N, N$-dimethylformamide and dimethyl sulfoxide, as opposed to their parent PHAs. As expected, modified PHAs are more hydrophilic than their parent compounds.

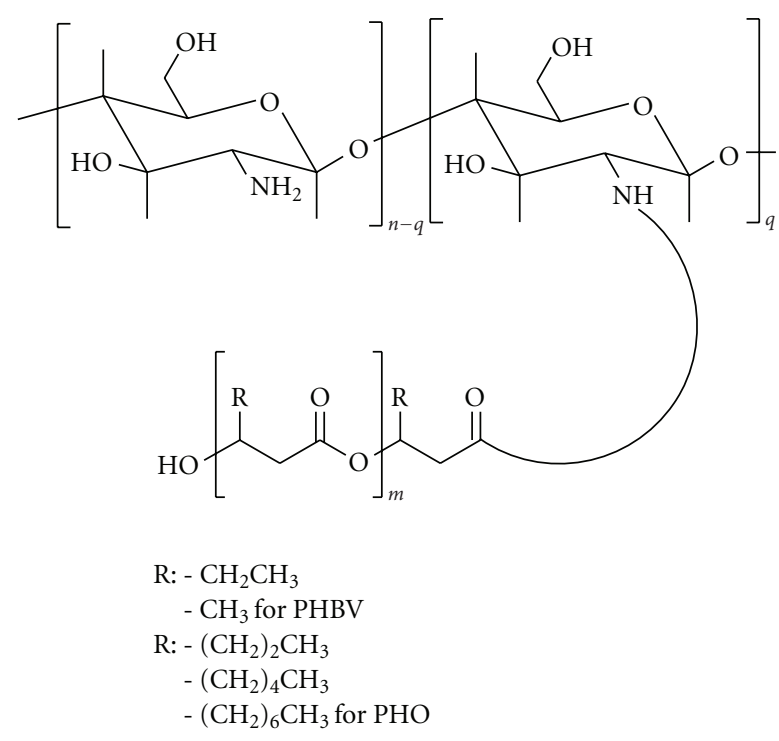

Figure 6: Chitosan-g-PHBV graft copolymer.

4.4.3. PEG Grafting. Diazo linkaged PEG, a polyazoester synthesized by the reaction of PEG and 4,4'-azobis(4cyanopentanoyl chloride) creates PEG macroradicals which is easily attack to the double bonds of the unsaturated PHA to obtain the PHA-g-PEG cross-linked graft copolymers [50]. PHAs containing double bonds in the side chain (PHA-DB) were obtained by cofeeding Pseudomonas oleovorans with a mixture of nonanoic acid and anchovy (hamci) oily acid (in weight ratios of 50/50 and 70/30). PHA-DB was thermally grafted with a [50].

Graft copolymers of the saturated mclPHAs can be synthesized by using macroradicals via $\mathrm{H}$-abstraction from the tertiary carbon of the polyester $[51,52]$. Similarily, macroradicals onto the PHAs are induced by the UV irradiation via $\mathrm{H}$-abstraction in the presence of a PEG-macromonomer to prepare PEG-g-PHO graft copolymers [53, 54]. Homogeneous solutions of poly(3-hydroxyoctanoate) (PHO) and the monoacrylate-poly(ethylene glycol) (PEGMA) monomer in chloroform were irradiated with UV light to obtain PEGMA-grafted PHO (PEGMA-g-PHO) copolymers. The results of the protein adsorption and platelet adhesion tests show that the blood compatibility was also enhanced by grafting the PEGMA chains. The adsorption of proteins and platelets was increasingly suppressed, as the grafting degree of PEGMA onto PHO increased. Glycerol 1,3-diglycerol diacrylate-grafted poly(3-hydroxyoctanoate) copolymers are also prepared by heating homogeneous solutions of PHO, diacrylate monomer, and benzoyl peroxide initiator [55]. The resulting copolymers have enhanced thermal properties and mechanical strengths. The surfaces and the bulk of the graft copolymers became more hydrophilic as the diglyceroldiacrylate grafting density in the copolymer increased. Many studies have reported that hydrophilic surfaces, such as those of hydro gels and PEG-grafted polymers, suppress protein adsorption and platelet adhesion. The surfaces of this graft copolymers become more hydrophilic with grafted 
TABLE 2: Methods for the synthesis of the amphiphilic PHAs.

\begin{tabular}{|c|c|c|c|}
\hline PHA & Synthesis & Product & Reference \\
\hline PHB & $\begin{array}{l}\text { Transesterification with } \\
\text { mPEG2000 (in melt) }\end{array}$ & PHB-b-PEG & {$[25]$} \\
\hline PHB & $\begin{array}{l}\text { Transesterification with } \\
\text { PEG2000 (in solution) }\end{array}$ & PHB-g-PEG & [29] \\
\hline PHB & $\begin{array}{l}\text { Transesterification with } \\
\text { Diethylene glycol (in melt) }\end{array}$ & PHB-diol & {$[26]$} \\
\hline $\mathrm{PHO}$ & $\begin{array}{l}\text { UV-irradiation with } \\
\text { methacrylated-PEG }\end{array}$ & PHO-g-PEG & {$[53]$} \\
\hline PHU & $\begin{array}{l}\text { UV-irradiation with } \\
\text { methacrylated-PEG }\end{array}$ & PHO-g-PEG & {$[54]$} \\
\hline $\mathrm{PHO}$ & $\begin{array}{l}\text { Free radical polymerization with } \\
\text { acrylate }\end{array}$ & PHO-g-Poly-glycerol diacrylate & {$[55]$} \\
\hline PHA-un- & $\begin{array}{l}\text { Free radical polymerization with } \\
\text { saturated polyazoester based on } \\
\text { PEG }\end{array}$ & PHA-g-PEG & {$[50]$} \\
\hline PHOU & $\begin{array}{l}\text { Epoxidation and reaction with } \\
\text { diethanol amine }\end{array}$ & PHA with pendant amine side groups & {$[42]$} \\
\hline $\mathrm{PHOU}$ & $\begin{array}{l}\text { Epoxidation and reaction with } \\
\text { hexamethylene diamine }\end{array}$ & Cross-linked PHOU & {$[41]$} \\
\hline PHB & Condensation with chitosan & PHB-g-chitosan & {$[45]$} \\
\hline $\mathrm{PHO}$ & Condensation with chitosan & PHO-chitosan & {$[46]$} \\
\hline PHOU & $\begin{array}{l}\text { Hydroxylation of the double } \\
\text { bonds }\end{array}$ & PHOU with pendant-OH & {$[34,37,38]$} \\
\hline PHOU & $\begin{array}{l}\text { Carboxylation of the double } \\
\text { bonds }\end{array}$ & PHOU with pendant- $\mathrm{COOH}$ & {$[35,36]$} \\
\hline PHB & $\begin{array}{l}\text { Urethane formation of PHB and } \\
\text { PCL containing dihydroxyl ends }\end{array}$ & PHB-g-PCL & {$[27,28]$} \\
\hline PHOU & $\begin{array}{l}\text { Thiol addition of thio-maltose to } \\
\text { double bonds }\end{array}$ & PHOU-g-sugar & {$[48]$} \\
\hline $\mathrm{PHOU}$ & $\begin{array}{l}\text { Esterification of carboxylated } \\
\text { PHOU with PEG }\end{array}$ & PHOU-g- PEG & {$[56]$} \\
\hline
\end{tabular}

diglycerol groups. These surface characteristics make this graft copolymer to prevent protein adsorption and platelet adhesion very effectively. Domenek et al. achieved the amphiphilic copolymer based on PHOU and PEG [56]. Carboxylic acid terminal groups in the side chains are reacted with PEG in the presence of dicyclohexyl carbamate at room temperature. Amphiphilic graft copolymer obtained is soluble in the mixture of $\mathrm{H}_{2} \mathrm{O} /$ acetone $(80 / 20)$ whereas precursor PHOU is not soluble.

As a summary, Table 2 indicates the sum of the chemical modification reactions to obtain amphiphilic PHAs.

\section{Conclusion}

Microbial polyesters are biocompatible and biodegradable hydrophobic natural thermoplastics. Amphiphilic PHAs from swollen in water to soluble in water are much more desirable in the drug delivery system and tissue engineering. In most attempts to synthesize amphiphilic PHAs, degradation of the polyester chain has been unavoidable. To obtain new amphiphilic PHAs with high molecular weight and their medical applications have been attractive for scientists.

\section{Acronyms}

PHA: Poly(3-hydroxy alkanoate)

PEG: $\quad$ Poly(ethylene glycol)

sclPHA: Short-chain-length PHA

mclPHA: Medium-chain-length PHA

lclPHA: long-chain-length PHA

PHB: $\quad$ Poly $([R]-3$-hydroxybutyric acid $)$

mPEG: Monomethoxy poly(ethylene glycol)

PHOU: Poly(3-hydroxy octanoate-co-10-undecenoate)

PHU: Poly(3-hydroxy-10-undecenoate)

PHBHx: Poly(3-hydroxy butyrate-co-3-hydroxy hexanoate)

PHON: Diethanol amin derivative of PHOU

PHOE: Epoxide derivative of $\mathrm{PHOU}$

PHA-Sy: PHA obtained from soybean oil

PHA-Cl: Chlorinated PHA

PHA-DB: Poly(3-hydroxyalkanoate)s containing double bonds in the side chain

PEGMA: Monoacrylate-poly(ethylene glycol)

PHBV: Poly(3-hydroxy butyrate-co-3-hydroxy valerate) 


\section{Acknowledgment}

This work was financially supported by TUBITAK (Grant no. 108T423) and ZKU Research Fund.

\section{References}

[1] R. Langer and D. A. Tirrell, "Designing materials for biology and medicine," Nature, vol. 428, no. 6982, pp. 487-492, 2004.

[2] S. Mitragotri and J. Lahann, "Physical approaches to biomaterial design," Nature Materials, vol. 8, no. 1, pp. 15-23, 2009.

[3] S. P. Valappil, S. K. Misra, A. Boccaccini, and I. Roy, "Biomedical applications of polyhydroxyalkanoates, an overview of animal testing and in vivo responses," Expert Review of Medical Devices, vol. 3, no. 6, pp. 853-868, 2006.

[4] A. J. Anderson and E. A. Dawes, "Occurrence, metabolism, metabolic role, and industrial uses of bacterial polyhydroxyalkanoates," Microbiological Reviews, vol. 54, no. 4, pp. 450472, 1990.

[5] R. W. Lenz and R. H. Marchessault, "Bacterial polyesters: biosynthesis, biodegradable plastics and biotechnology," Biomacromolecules, vol. 6, no. 1, pp. 1-8, 2005.

[6] B. Hazer and A. Steinbüchel, "Increased diversification of polyhydroxyalkanoates by modification reactions for industrial and medical applications," Applied Microbiology and Biotechnology, vol. 74, no. 1, pp. 1-12, 2007.

[7] K. Sudesh, H. Abe, and Y. Doi, "Synthesis, structure and properties of polyhydroxy alkanoates: biological polyesters," Progress in Polymer Science, vol. 25, pp. 1503-1555, 2000.

[8] A. Steinbüchel and B. Füchtenbusch, "Bacterial and other biological systems for polyester production," Trends in Biotechnology, vol. 16, no. 10, pp. 419-427, 1998.

[9] D. Y. Kim, W. K. Kim, M. G. Chung, and Y. H. Rhee, "Biosynthesis, modification, and biodegradation of bacterial mediumchain-length polyhydroxyalkanoates," Journal of Microbiology, vol. 45, no. 2, pp. 87-97, 2007.

[10] R. H. Marchessault, "Polyhydroxyalkanoate (PHA) History at Syracuse University and Beyond," Cellulose, vol. 16, pp. 357359, 2009.

[11] W. J. Orts, G. A. R. Nobes, J. Kawada, S. Nguyen, G.-E. Yu, and F. Ravenelle, "Poly(hydroxyalkanoates): biorefinery polymers with a whole range of applications. The work of Robert $\mathrm{H}$. Marchessault," Canadian Journal of Chemistry, vol. 86, no. 6, pp. 628-640, 2008.

[12] M. Zinn, B. Witholt, and T. Egli, "Occurrence, synthesis and medical application of bacterial polyhydroxyalkanoate," Advanced Drug Delivery Reviews, vol. 53, no. 1, pp. 5-21, 2001.

[13] Q. Wu, Y. Wang, and G.-Q. Chen, "Medical application of microbial biopolyesters polyhydroxyalkanoates," Artificial Cells, Blood Substitutes, and Biotechnology, vol. 37, no. 1, pp. $1-12,2009$.

[14] K. Ruth, G. de Roo, T. Egli, and Q. Ren, "Identification of two acyl-CoA synthetases from Pseudomonas putida GPo1: one is located at the surface of polyhydroxyalkanoates granules," Biomacromolecules, vol. 9, no. 6, pp. 1652-1659, 2008.

[15] A. Steinbuchel and H. E. Valentin, "Diversity of bacterial polyhydroxyalkanoic acids," FEMS Microbiology Letters, vol. 128, no. 3, pp. 219-228, 1995.

[16] S. Förster and M. Antonietti, "Amphiphilic block copolymers in structure-controlled nanomaterial hybrids," Advanced Materials, vol. 10, no. 3, pp. 195-217, 1998.
[17] N. Hadjichristidis, M. Pitsikalis, S. Pispas, and H. Iatrou, "Polymers with complex architecture by living anionic polymerization," Chemical Reviews, vol. 101, no. 12, pp. 37473792, 2001.

[18] K. J. Townsend, K. Busse, J. Kressler, and C. Scholz, "Contact angle, WAXS, and SAXS analysis of poly( $\beta$-hydroxybutyrate) and poly(ethylene glycol) block copolymers obtained via Azotobacter vinelandii UWD," Biotechnology Progress, vol. 21, no. 3, pp. 959-964, 2005.

[19] L. J. R. Foster, "Biosynthesis, properties and potential of natural-synthetic hybrids of polyhydroxyalkanoates and polyethylene glycols," Applied Microbiology and Biotechnology, vol. 75, no. 6, pp. 1241-1247, 2007.

[20] B. Hazer, "Chemical modification of synthetic and biosynthetic polyesters," in Biopolymers, A. Steinbuchel, Ed., vol. 10, chapter 6, pp. 181-208, John Wiley \& Sons, Weinheim, Germany, 2003.

[21] S. Ilter, B. Hazer, M. Borcakli, and O. Atici, "Graft copolymerisation of methyl methacrylate onto a bacterial polyester containing unsaturated side chains," Macromolecular Chemistry and Physics, vol. 202, no. 11, pp. 2281-2286, 2001.

[22] B. Hazer, "Chemical modification of bacterial polyester," Current Trends in Polymer Science, vol. 7, pp. 131-138, 2002.

[23] B. Cakmakli, B. Hazer, and M. Borcakli, "Poly(styrene peroxide) and poly(methyl methacrylate peroxide) for grafting on unsaturated bacterial polyesters," Macromolecular Bioscience, vol. 1, no. 8, pp. 348-354, 2001.

[24] B. Hazer, "Poly( $\beta$-hydroxynonanoate) and polystyrene or poly(methyl methacrylate) graft copolymers: microstructure characteristics and mechanical and thermal behavior," Macromolecular Chemistry and Physics, vol. 197, no. 2, pp. 431-441, 1996.

[25] F. Ravenelle and R. H. Marchessault, "One-step synthesis of amphiphilic diblock copolymers from bacterial poly([R]-3hydroxybutyric acid)," Biomacromolecules, vol. 3, no. 5, pp. 1057-1064, 2002.

[26] T. D. Hirt, P. Neuenschwander, and U. W. Suter, "Telechelic diols from poly[(R)-3-hydroxybutyric acid] and poly[(R)3-hydroxy butyric acid]-co-[(R)-3-hydroxyvaleric acid]," Macromolecular Chemistry and Physics, vol. 197, no. 5, pp. 1609-1614, 1996.

[27] G. R. Saad, "Calorimetric and dielectric study of the segmented biodegradable poly(ester-urethane)s based on bacterial poly[(R)-3-hydroxybutyrate]," Macromolecular Bioscience, vol. 1, no. 9, pp. 387-396, 2001.

[28] G. R. Saad, Y. J. Lee, and H. Seliger, "Synthesis and characterization of biodegradable poly(ester-urethanes) based on bacterial poly(R-3-hydroxybutyrate)," Journal of Applied Polymer Science, vol. 83, no. 4, pp. 703-718, 2001.

[29] H. Erduranl, B. Hazer, and M. Borcakli, "Post polymerization of saturated and unsaturated poly(3-hydroxy alkanoate)s," Macromolecular Symposia, vol. 269, no. 1, pp. 161-169, 2008.

[30] B. Hazer, O. Torul, M. Borcakli, R. W. Lenz, R. C. Fuller, and S. D. Goodwin, "Bacterial production of polyesters from free fatty acids obtained from natural oils by Pseudomonas oleovorans," Journal of Environmental Polymer Degradation, vol. 6, no. 2, pp. 109-113, 1998.

[31] R. D. Ashby and T. A. Foglia, "Poly(hydroxyalkanoate) biosynthesis from triglyceride substrates," Applied Microbiology and Biotechnology, vol. 49, no. 4, pp. 431-437, 1998.

[32] K. Fritzsche and R. W. Lenz, "Production of unsaturated polyesters by Pseudomonas oleovorans," International Journal of Biological Macromolecules, vol. 12, no. 2, pp. 85-91, 1990. 
[33] Y. B. Kim, R. W. Lenz, and R. C. Fuller, "Poly-3hydroxyalkanoates containing unsaturated repeating units produced by Pseudomonas oleovorans," Journal of Polymer Science Part A, vol. 33, pp. 1367-1374, 1995.

[34] M. Y. Lee, W. H. Park, and R. W. Lenz, "Hydrophilic bacterial polyesters modified with pendant hydroxyl groups," Polymer, vol. 41, no. 5, pp. 1703-1709, 2000.

[35] M. Y. Lee and W. H. Park, "Preparation of bacterial copolyesters with improved hydrophilicity by carboxylation," Macromolecular Chemistry and Physics, vol. 201, no. 18, pp. 2771-2774, 2000.

[36] D. J. Stigers and G. N. Tew, "Poly(3-hydroxyalkanoate)s functionalized with carboxylic acid groups in the side chain," Biomacromolecules, vol. 4, no. 2, pp. 193-195, 2003.

[37] M. S. Eroglu, B. Hazer, T. Ozturk, and T. Caykara, "Hydroxylation of pendant vinyl groups of poly(3-hydroxy undec-10enoate) in high yield," Journal of Applied Polymer Science, vol. 97, no. 5, pp. 2132-2139, 2005.

[38] E. Renard, A. Poux, L. Timbart, V. Langlois, and P. Guérin, "Preparation of a novel artificial bacterial polyester modified with pendant hydroxyl groups," Biomacromolecules, vol. 6, no. 2, pp. 891-896, 2005.

[39] D. M. Zhang, F. Z. Cui, Z. S. Luo, Y. B. Lin, K. Zhao, and G. Q. Chen, "Wettability improvement of bacterial polyhydroxyalkanoates via ion implantation," Surface and Coatings Technology, vol. 131, pp. 350-354, 2000.

[40] M.-M. Bear, M.-A. Leboucher-Durand, V. Langlois, R. W. Lenz, S. Goodwin, and P. Guerin, "Bacterial poly-3hydroxyalkenoates with epoxy groups in the side chains," Reactive and Functional Polymers, vol. 34, no. 1, pp. 65-77, 1997.

[41] M. Y. Lee, S. Y. Cha, and W. H. Park, "Crosslinking of microbial copolyesters with pendant epoxide groups by diamine," Polymer, vol. 40, no. 13, pp. 3787-3793, 1999.

[42] J. Sparks and C. Scholz, "Synthesis and characterization of a cationic Poly( $\beta$-hydroxyalkanoate)," Biomacromolecules, vol. 9, no. 8, pp. 2091-2096, 2008.

[43] A. H. Arkin, B. Hazer, and M. Borcakli, "Chlorination of poly(3-hydroxy alkanoates) containing unsaturated side chains," Macromolecules, vol. 33, no. 9, pp. 3219-3223, 2000.

[44] A. H. Arkin and B. Hazer, "Chemical modification of chlorinated microbial polyesters," Biomacromolecules, vol. 3, no. 6, pp. 1327-1335, 2002.

[45] G. Yu, F. G. Morin, G. A. R. Nobes, and R. H. Marchessault, "Degree of acetylation of chitin and extent of grafting PHB on chitosan determined by solid state $15 \mathrm{~N}$ NMR," Macromolecules, vol. 32, no. 2, pp. 518-520, 1999.

[46] H. Arslan, B. Hazer, and S. C. Yoon, "Grafting of poly(3hydroxyalkanoate) and linoleic acid onto chitosan," Journal of Applied Polymer Science, vol. 103, no. 1, pp. 81-89, 2007.

[47] S. Muthukrishnan, G. Jutz, X. André, H. Mori, and A. H. E. Müller, "Synthesis of hyperbranched glycopolymers via selfcondensing atom transfer radical copolymerization of a sugarcarrying acrylate," Macromolecules, vol. 38, no. 1, pp. 9-18, 2005.

[48] M. Constantin, C. I. Simionescu, A. Carpov, E. Samain, and H. Driguez, "Chemical modification of poly(hydroxyalkanoates). Copolymers bearing pendant sugars," Macromolecular Rapid Communications, vol. 20, no. 2, pp. 91-94, 1999.

[49] Y. B. Kim, R. W. Lenz, and R. C. Fuller, "Poly $(\beta-$ hydroxyalkanoate) copolymers containing brominated repeating units produced by Pseudomonas oleovorans," Macromolecules, vol. 25, no. 7, pp. 1852-1857, 1992.
[50] B. Hazer, R. W. Lenz, B. Çakmaklı, M. Borcaklı, and H. Koçer, "Preparation of poly(ethylene glycol) grafted poly(3hydroxyalkanoate) networks," Macromolecular Chemistry and Physics, vol. 200, no. 8, pp. 1903-1907, 1999.

[51] B. Hazer, "Poly( $\beta$-hydroxynonanoate) and polystyrene or poly(methyl methacrylate) graft copolymers: microstructure characteristics and mechanical and thermal behavior," Macromolecular Chemistry and Physics, vol. 197, no. 2, pp. 431-441, 1996.

[52] S. Ilter, B. Hazer, M. Borcakli, and O. Atici, "Graft copolymerisation of methyl methacrylate onto a bacterial polyester containing unsaturated side chains," Macromolecular Chemistry and Physics, vol. 202, no. 11, pp. 2281-2286, 2001.

[53] H. W. Kim, C. W. Chung, and Y. H. Rhee, "UV-induced graft copolymerization of monoacrylate-poly(ethylene glycol) onto poly(3-hydroxyoctanoate) to reduce protein adsorption and platelet adhesion," International Journal of Biological Macromolecules, vol. 35, no. 1-2, pp. 47-53, 2005.

[54] C. W. Chung, H. W. Kim, Y. B. Kim, and Y. H. Rhee, "Poly(ethylene glycol)-grafted poly(3-hydroxyundecenoate) networks for enhanced blood compatibility," International Journal of Biological Macromolecules, vol. 32, no. 1-2, pp. 1722, 2003.

[55] H. W. Kim, M. G. Chung, Y. B. Kim, and Y. H. Rhee, "Graft copolymerization of glycerol 1,3-diglycerolate diacrylate onto poly(3-hydroxyoctanoate) to improve physical properties and biocompatibility," International Journal of Biological Macromolecules, vol. 43, no. 3, pp. 307-313, 2008.

[56] S. Domenek, V. Langlois, and E. Renard, "Bacterial polyesters grafted with poly(ethylene glycol): behaviour in aqueous media," Polymer Degradation and Stability, vol. 92, no. 7, pp. 1384-1392, 2007. 

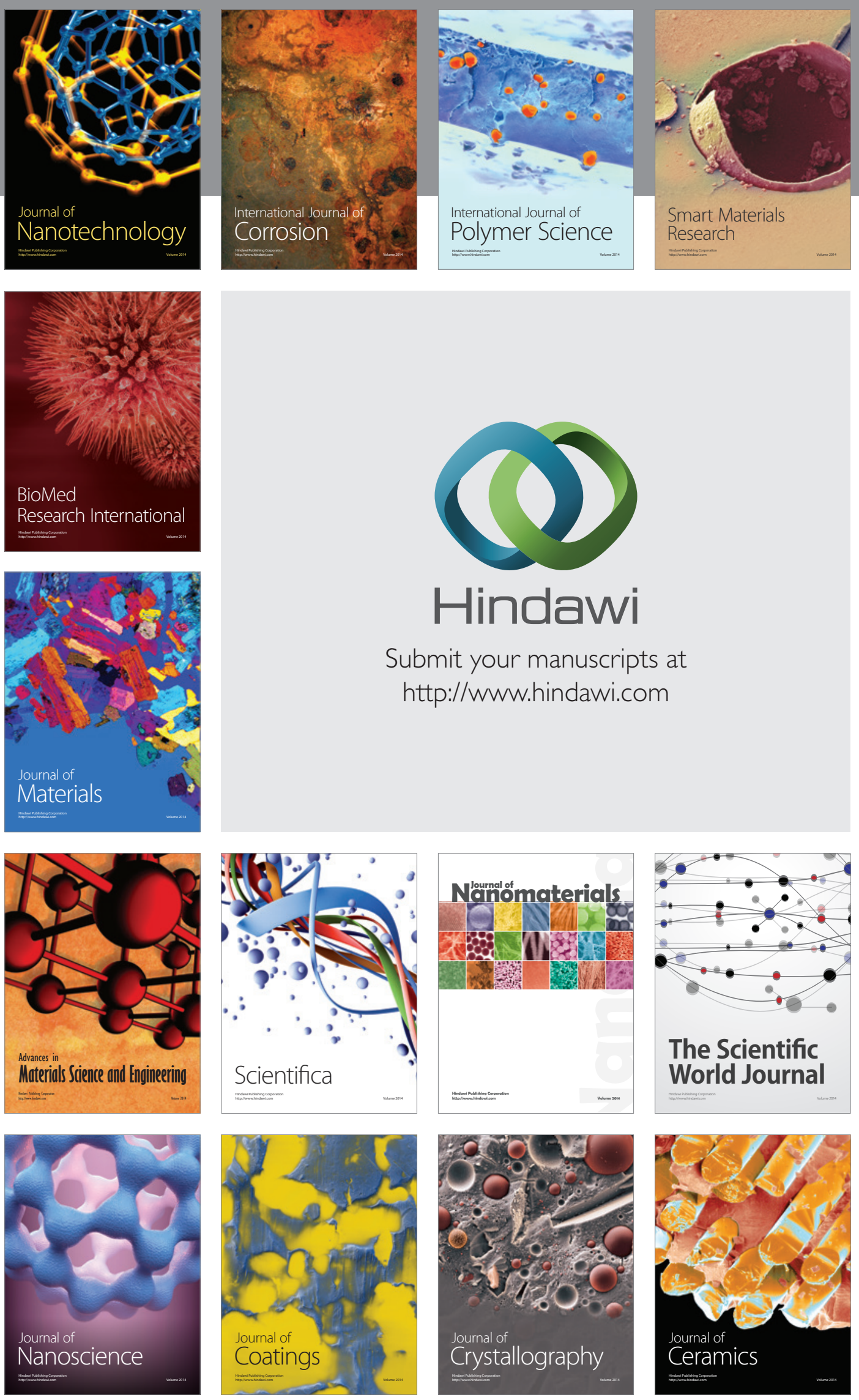

The Scientific World Journal

Submit your manuscripts at

http://www.hindawi.com

\section{World Journal}

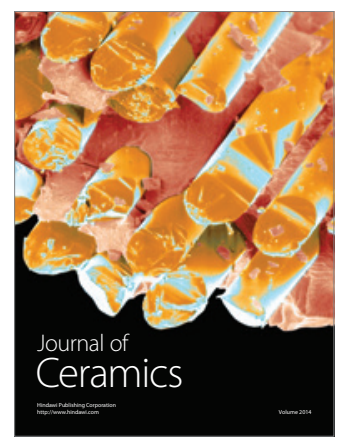

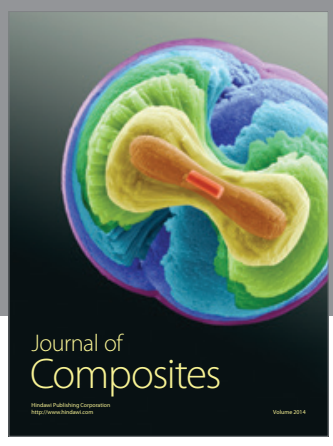
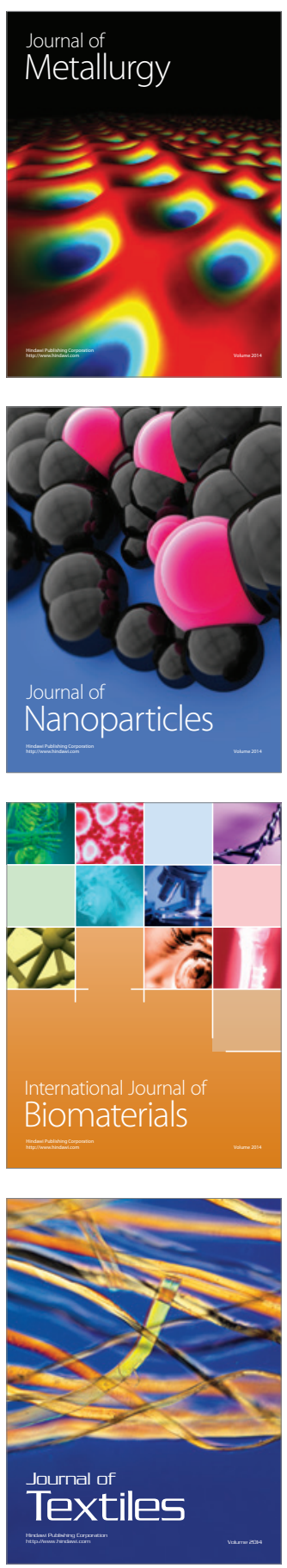